\title{
Inquire, Imagine, Innovate: A Scholarly Approach to Curriculum Practice
}

Michelle Yeo, Jennifer Boman, Julie A. Mooney, Andrea Phillipson, Luciana da Rosa dos Santos, Erika E. Smith

This paper describes the development of a three-phase approach our team of educational developers finds useful in curriculum projects in our Teaching and Learning Centre. Informed by the literature on the importance of flexibility and iteration (Knight, 2001; Wolf, 2007) and an orientation towards Appreciative Inquiry (Srivastra \& Cooperrider, 1990), we contextualize our work in relation to others in the Canadian educational development landscape. Additionally, we highlight the importance of recognizing micro, meso, and macro levels of influence in institutions of higher education (Poole \& Simmons, 2013). We describe our Inquire, Imagine, and Innovate, or 3-I, model for curriculum consultation, positioned by fictionalized vignettes demonstrating how each phase is applied. We conclude the paper by indicating where we are continuing to develop this work.

Dans cet article, nous décrivons l'élaboration d'une approche en trois phases que notre équipe de concepteurs pédagogiques juge utile pour les programmes de notre centre d'enseignement et d'apprentissage. À partir de la recherche sur l'importance de la flexibilité et l'itération (Knight, 2001; Wolf, 2007) et d'un penchant pour l'interrogation appréciative (Srivastva et Cooperrider, 1990), nous replaçons notre recherche dans le contexte d'autres travaux dans le domaine du perfectionnement de l'enseignement au Canada. De plus, nous insistons sur l'importance de reconnaître les micro-, macro- et méso-niveaux d'influence dans les établissements d'enseignement supérieur (Poole et Simmons, 2013). Nous décrivons notre modèle 3-I - Interrogation, Imagination, Innovation - pour la consultation sur les programmes, en montrant, au moyen de fictions sur vignettes, comment chaque phrase se déroule. En conclusion, nous indiquons quelles sont les suites que nous donnons à ce travail.

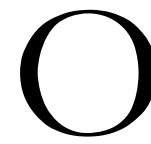

ne of the many roles educational developers undertake is curriculum consultation which includes a broad spectrum of activities from a single consultation with a faculty member working on a course outline, to an ongoing programmatic design or redesign with an entire department. The educational development team within our Teaching and Learning Centre
(TLC) regularly engages in such work. In this paper, we describe a model for curriculum redesign that we developed to guide projects that span the curriculum spectrum. Although we intend to share this model primarily with the educational development community, faculty members or teams redesigning courses or programs may also find it useful. Above all, we mean to encourage all people involved in 
curriculum development to reflect on the process, as we have found such collaborative reflection valuable to making our tacit knowledge explicit.

Individuals and teams must adapt curriculum design resources to suit their specific institutions and practices. At our institution, we send out a yearly call for formal course and program redesign projects. A committee adjudicates applications based on a set of criteria and grants successful applicants one to two course releases to do the work. The educational development team then works with individuals and departments on selected curriculum initiatives through a formal redesign process, and simultaneously conducts ad hoc curriculum consultations as faculty members request them.

Our work with departmental teams in particular prompted us to develop the Inquire, Imagine, Innovate (3-I) model we describe in this paper. We wanted to refine our curriculum design processes to help us better navigate curricular projects characterized by complex learning and infrastructure, especially those with broader programmatic or institutional implications. We realized we needed an inquiry-oriented approach that engaged the student voice, incorporated all members of the team, helped to resolve intra-departmental differences, and avoided foreclosing too quickly on solutions. Because it captures a dynamic process, the 3-I model allows us to achieve these multifaceted goals. Although we developed this model to guide program-level curriculum redesign projects, it is effective for both small and large-scale projects.

We start this paper with a brief description of the literature that informed our approach, highlighting the micro, meso, and macro levels of influence at work in curricular redesign. Next, we introduce the Inquire, Imagine, and Innovate (3-I) model that we developed for curriculum consultation. This model depicts a three-phase process, and we provide fictionalized vignettes of our own practice to serve as examples of how to apply each phase. Finally, we indicate future directions for the model and educational development practice.

\section{Literature Review}

Hubball, Pearson, and Clarke (2013) note a scarcity of published scholarship about the theory and practice of program-level curriculum renewal initiatives. Two texts from our earlier work particularly influenced the model we describe in the present article: Knight's (2001) theoretical exploration of a "process model" of curriculum planning and Wolf's (2007) description of the University of Guelph's curriculum assessment and development approach.

Knight's (2001) approach to curriculum development is especially helpful for moving beyond a rigid outcomes-focused approach that does not always resonate well with faculty. He argues that learning in higher education is complex and requires curricula that are "coherent and progressive" ( $p$. 370). The problem he identifies is that the most common method for achieving coherence is rational curriculum planning, a "systematic approach" that privileges efficiency in its "tight-coupling" of outcomes and their means, leaving no space for creativity or innovation, and no time for the slow learning that a complex education demands. Knight proposes that we take literature on complex systems seriously, considering how learning in higher education might be "indeterminate, non-linear, and contingent" (p. 370), and thus ill-suited to the certainty and rigidity of rational curriculum planning. Instead of beginning from abstract ideas, attempting to articulate learning outcomes to which all elements of curriculum become bound, Knight proposes that we might achieve curricular coherence by starting with the concrete practices that produce desired outcomes, "to provide ingredients from which a meal can be created, rather than to insist on cooking to a recipe" (p. 375). Curriculum coherence thus emerges not because educators are made accountable through outcomes that align with program goals, but because these professionals are trusted as those who recognize best what good learning, teaching, and assessment in their subject areas look like (p. 376). 
They can then purposefully distribute these experiences throughout the curriculum.

Whereas Knight (2001) provides a high-level, theoretical rationale for approaching curriculum in a particular way, Wolf (2007) articulates the more practical business of "engag[ing] faculty members in a reflective process" (p. 16). Consistent with Knight's concerns, Wolf wants to avoid "forcing a systematized outcome-based approach" on faculty (p. 19). He instead draws them into a three-phase inquiry through which they claim ownership over establishing priorities and deciding on action. He describes the process as "flexible" (p. 16), "facultydriven, data-informed, and educational development-supported" (p. 17). This characterization fits well with our institutional context, as do the basic contours of the University of Guelph model. Educational developers ask faculty to partake in Curriculum Visioning, which includes data collection that informs program goals. The faculty then work on Curriculum Development, including curriculum mapping that informs the (re)development of the program structure. Finally, they ensure Alignment, Coordination, and Development by testing and strengthening congruences between the first two phases. Faculty intentionally dwell within each phase, and educational developers support them in a flexible manner, providing a variety of models to aid their exploration.

While Wolf's (2007) approach seemed generally appropriate for our context, we wondered what it might look like to think about "visioning" as an idealistic phase, one distinct from yet ultimately informing the pragmatics of data collection. In heeding Knight's (2001) caution, we were wary of limiting the "visioning" phase to an articulation of program goals, which is the definition suggested by Wolf's and others' models (e.g., Gwenna Moss Centre for Teaching and Learning, n.d.). Instead, we turned to Appreciative Inquiry as this idea has been operationalized in the Strengths, Opportunities, Aspirations, Results (SOAR) model (Stavros,
Cooperrider, \& Kelley, 2003; Stavros \& Hinrichs, 2011).

\section{Our Turn to Appreciative Inquiry}

We adapted the SOAR model rather than adopting it in its entirety. Appreciative Inquiry, much like Wolf's vision for curriculum development, is based upon open dialogue for creating a shared vision for organizational change (Srivastra \& Cooperrider, 1990). It is dedicated to generating buy-in from all concerned parties which translates well into our educational development work. However, we were less convinced about Appreciative Inquiry's stringent focus on positives, and the insistence that this optimism is the only way to make space for thinking outside existing boundaries and barriers. Stavros et al. (2003) note that SOAR emerged as a direct critique of the SWOT (strengths, weaknesses, opportunities, threats) model of analyzing organizational structures. They argue that, because a SWOT analysis is so absorbed in articulating the negative (the weaknesses and threats), this traditional approach to strategic planning is uninspiring and results in low engagement and clouded vision. As a modification to SWOT, we tend to find the language of SWOC (strengths, weaknesses, opportunities, challenges) more appropriate for working with faculty members. While we acknowledge that there is some debate in the literature between the SWOT, SWOC, and SOAR approaches, we have found in our facilitation of data-collection that any of these heuristics can be useful, and that giving stakeholders an opportunity to voice their concerns does not necessarily impede their ability to be imaginative further into the process.

What we take from the Appreciative Inquiry approach is not a strict dogma about replacing SWOT, but rather an orientation that values thinking beyond existing organizational constraints. Stavros and Hinrichs (2011) provide a way of thinking more expansively when they describe the 5-I approach of SOAR. They recommend organizing strategic planning processes around five stages: Initiate, 
Inquire, Imagine, Innovate, and Inspire to Implement. Unsurprisingly, all five stages are rooted in a positive orientation, but their vision for the Imagine phase struck us as unique for curriculum development. When imagining a positive future, participants focus on possibilities without concern for barriers. Creativity thus inspires their planning. This 'I' became our inspiration and focus. In an attempt to simplify overly complex and rigid curriculum development processes, we adopted and adapted a 3-I model of Inquire, Imagine, and Innovate.

\section{Micro, Meso, and Macro Framework}

Before we proceed to the model, it is important to point out that we view curriculum development work through the lens of its impact on different levels of the institution. To do so, we turned to Poole and Simmons (2013), who conceptualize the structure of higher education institutions into three levels of influence: micro, meso, and macro.

At a micro-level, instructors, students, and staff act individually to enhance teaching and learning practices. In a curriculum development setting, this is where work on individual courses takes place, often by shaping course objectives, structuring assignments, and designing learning activities so that the main components of a course are in alignment. Departments sit at the meso-level of the organization. This is a prime space where instructors collaborate on programmatic decisions that will affect programs and degrees. For instance, program curriculum maps allow instructors to identify intersections between courses and foster better student experience by purposefully building learning activities on previous learning. Finally, Poole and Simmons (2013) identify "senior administrators governing the entire institution" (p. 121) as the macro-level. Their strategic decisions impact the work of curriculum development across the institution, such as when they create policies that establish official academic schedules.

Although the micro, meso, and macro framework was first proposed to describe the impact of Scholarship of Teaching and Learning within higher education institutions (Simmons, 2016), it is also a useful tool for guiding and delimiting the scope of curriculum development work. Its value becomes even more visible when considering the perspective taken by Williams et al. (2013), who include the notion of interactions within and between each level. These synergies and connections exist in each level, and educational developers can use this framework to conceptualize issues and influences affecting curriculum work. More importantly, the framework serves as a communication tool to stakeholders as it illustrates the various contexts involved in course and program redesign.

\section{The 3-I Model}

In this section, we introduce our Inquire, Imagine, Innovate model by describing each phase and illustrating each with a vignette of a possible scenario. Figure 1 shows a visual representation of the process, which we share with faculty members at the initiation of the project, along with expected timelines. Typically, the Inquire phase is the longest, often twice as long as each of the other two phases. In a project spanning an academic year, we might spend a whole four-month semester on Inquire, and then two months or so each on Imagine and Innovate. These timelines can be scaled up or down depending on the project. 


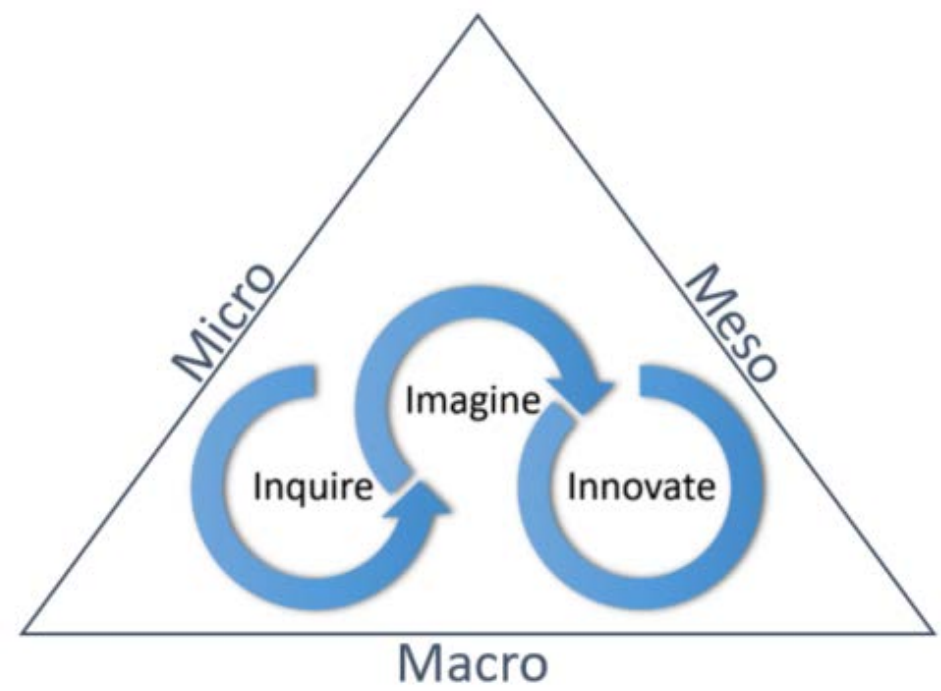

Figure 1. The 3-I model. This figure illustrates the 3-I Process within the Micro, Meso, Macro Framework.

\section{Inquire}

During a SWOC (strengths, weaknesses,
opportunities, challenges) exercise facilitated for a
course redesign project, the instructors suggest that
the poor success rate is due to student apathy about
the course and confusion about its relevance to the
broader program. They wonder if the students simply
do not devote enough study time to ultimately be
successful. There is much more data to collect in the
Inquire phase, however, and during focus group
interviews, educational developers discover that
students actually love the textbook and, in most
cases, can articulate the relevance of the course well.
While study time is indeed an issue, an unknown
problem was that from the student perspective, the
labs did not align with the rest of the coursework,
which comes as a surprise to the instructors.

The Inquire stage is characterized by an active investigation into the relevant curriculum issues that have prompted the redesign request. In this stage, we engage all relevant stakeholders in defining key problems and questions, articulating what currently works well, determining student needs and feedback, and eliciting faculty members' observations and perceptions. We also discuss the stakeholders' definition of success for the completed curriculum work and help perform research that will support the process, such as conducting environmental scans or consulting scholarly literature that describes relevant disciplinary pedagogical issues.

The key activity in the Inquire stage is for the educational developer to support information and data-gathering. The specific data-gathering methods depend on the questions posed, but common examples include surveys, focus groups, and interviews with students and/or faculty members. In our experience, faculty members are often willing to set aside time during their class period so that we can gather information about student perceptions of the course and/or program. Those who find heuristics like SWOT, SWOC, or SOAR to be useful may employ these to frame their information-gathering and facilitation strategies. We receive a good level of student participation and capture diverse views by administering a short individual survey to students, followed immediately by a group conversation that allows for elaboration and more in-depth discussion. Depending on the issue at hand, we have also used a combination of individual interviews and a large group discussion to obtain faculty members' perceptions of what is working well within a program and where some of the opportunities for growth and change might be. A third activity that we use regularly 
is curriculum mapping. We create a visual map of the outcomes, assessments, and learning activities across the program. Instructors are asked to contribute data from their own individual courses, which we then feed into the larger map. We also commonly use this form of mapping for micro level curriculum projects such as the design or redesign of individual courses.

The process of gathering information helps to further clarify the key issues driving the curriculum change. It also presents an opportunity to more fully engage relevant stakeholders, some of whose voices might not otherwise be heard. Similarly, deep inquiry helps ensure that issues that might otherwise be invisible or unnoticed are also surfaced so that they can be addressed during the later stages of the process. Dwelling in the Inquire phase also helps us to ensure meaningful collaboration, even among skeptics. In groups where some participants are wary about substantial change, or where there are opposing perspectives, it can be helpful to remind participants that the Inquire stage is an opportunity to ask questions, that no changes will be made immediately, and that these future decisions will be based on the evidence being collected.

The key strategy in the Inquire stage is exploration and holding back from jumping to conclusions or making decisions. Often, programs or participants want to start brainstorming solutions without an adequate investigation into the problem. In our experience working with departments, we commonly found that once the data are assembled and our colleagues see the larger picture, they are able to attain clarity on the nature of the problems identified. This clarity invites colleagues to consider different kinds of solutions than those they may have first envisioned. We should also note that, despite our desire not to foreclose on solutions too soon, we respect our colleagues' need to express suggestions as they occur to them. In our facilitation, we maintain a robust 'parking lot' where ideas for future phases are noted, so they are not lost.
Imagine

A program wants to Indigenize introductory coursework, adding more relevant content and appropriate pedagogies. The Inquire phase, consisting of consultation with our campus office responsible for Indigenization, reveals course structures that might be recast from an Indigenous perspective. The Imagine phase allows the department to step outside of disciplinary and institutional norms to start with a blank page and ask, "What could these courses look like with an Indigenous pedagogical approach? What does the content look like when Indigenous voices are included?" We consider all the possibilities we can dream before re-introducing constraints such as transfer to other institutions. While those constraints may influence decisions made, a fully re-imagined offering provides new possibilities not seen at the beginning of the process. Given a landscape in which Canadian postsecondary institutions profess a strong commitment to Indigenization initiatives, an opportunity exists for substantive change to course designs.

The Imagine stage invites faculty members to engage in open conversations within a creative process designed to generate ideas and encourage divergent thinking. The key activity in this stage is creative brainstorming that temporarily sets aside issues of structural limitations in order to explore as many potential solutions, frameworks, structures, approaches, or pedagogies as possible.

Curricular issues that arise from the data collected in the Inquire stage are the starting point for the Imagine stage. We remind faculty members about any solutions that may have been suggested during the Inquire stage, but that were set aside for further consideration later in the process. Generally, we compile these suggestions and other data in a digital file that we can share with faculty members before an Imagine meeting, giving them time to analyze the data and consider their own interpretations of it. During an Imagine meeting, we facilitate brainstorming, often using tools such as 
whiteboards, shared digital documents, and individual reflexive writing. Guiding questions for this stage might include: "What surprised you most about the data? How does this influence your understanding of the problem?" and "Given the problem that these data make clear to you, and assuming, for now, unlimited resources, infrastructure, and time, what solution would you choose to address the problem?"

The conversation may reveal various interpretations of the data and a wide array of solutions to several curricular issues at the micro, meso, and macro levels. The group may be tempted to prioritize the problems and focus on solving what they deem most important. However, during the Imagine stage, it is important to allow as many interpretations and solutions to be voiced as possible. This stage is a generative one, calling upon faculty members to think beyond their usual curricular approaches and frameworks. If conflict among proposed solutions arises, the educational developer's role as an outsider to the department can prove invaluable. Our neutral position within the conversation allows us to remind faculty colleagues of the purpose of the Imagine stage. We can steer the conversation back to an open, exploratory tone, inclusive of any interpretation and priority expressed, and reassuring that the opportunity for narrowing the focus and ranking priorities occurs in the Innovate stage.

\section{Innovate}

During the Inquire and Imagine phases of the redesign of a multi-section first year course that was struggling with diverse interests of instructors and students, we determined that there was a need for more articulation and cooperation between sections, as well as buy-in from faculty in the department to teach the course. Concomitantly, it was apparent that there was a push at the meso- and macro-levels to address budgetary constraints. For the Innovate phase, we explored pedagogical approaches that would support learning objectives while also addressing the issues we identified in the previous phases. The resulting structure consisted of a blend between large lectures that cover core material and smaller seminar classes that introduce common case studies. Happily, this was also a less expensive structure. When presented in a department meeting for feedback, there was strong support for the changes, which were described as giving 'new blood' to the course.

The Innovate stage focuses on application and integration of outcomes from the two earlier stages to make informed decisions about what curricular elements need to change and how to implement these changes. In this stage, we work with stakeholders integrating all the relevant evidence from the Inquire phase, including any qualitative and quantitative data collected via surveys, focus groups, or interviews. Where appropriate, we draw relevant information from the grey literature (e.g., reports, policies, etc.) or other related research to inform decisions about whether the possibilities imagined are feasible, beneficial, or desirable, and how they can be implemented.

A key activity within the Innovate stage is to facilitate faculty members' integration and application of the best available evidence, informing their decisions about meaningful pedagogical change. The goal of the Innovate stage is to transform existing pedagogical approaches using design elements that are both necessary and feasible within any identified constraints. Through a facilitated process, we ask stakeholders to consider such questions such as "What changes will you make to create maximum impact within existing constraints?" and, "What barriers might need to be removed?" We then facilitate specific decisions by engaging key stakeholders in priority-setting activities like ranking the changes that are the most pressing, feasible, or impactful. If using a SWOT, SWOC or SOAR approach, the facilitator may return to heuristic and related information-gathering outcomes to inform the decision-making process. Another valuable step is engaging key individuals or groups in consensusbuilding activities that help promote stakeholder buy-in before and during the implementation of 
selected innovation. This includes identifying roles that will be required to support this innovation in the future. A focus of stakeholder engagement activities as well as facilitated discussions can also serve as advocacy strategies that promote the desired change and can help individuals or teams deal with change management and the transitional periods (e.g., Rutgers, 2018).

Within the Innovate stage, (re)design of pedagogical approaches may occur at the micro, meso, and/or macro scale, reinforcing the integrated nature of these levels of influence. Approaches at the micro level often reflect common foundations of instructional design that focus on reworking instructional strategies, course materials, forms of assessment, or modes of delivery (e.g., flipped or blended classes or experiential learning opportunities) for a particular course. The (re)design may also engage at a wider systems level (e.g., meso and macro) by triggering revisions to the scope and sequence of a program. Such structural changes may have implications for scheduling, pre-requisites, and pathways to completion. To ensure that the (re)designed innovations are achievable and sustainable, an important step of the innovate stage is to proactively encourage stakeholders to plan how they will support short-term and long-term implementation of innovations by identifying and leveraging the required resources.

\section{Discussion}

We discovered a way to shape the process of adapting and creating the model using a scholarly and pragmatic approach to curriculum projects that appreciates complexity and encourages contribution from all stakeholders. One problem we routinely encounter is that faculty members have their own perceptions of what problems exist in their context and tend to rush towards decision-making in their day-to-day mode of trial and error. While this is understandable in everyday teaching practice, for these resource-intensive projects we want to take a more intentional approach and slow the process down. Thus, breaking out the phases into Inquire, Imagine, and Innovate helps us to hold back the decision-making, reassuring faculty members that we will get there, while encouraging the team to dwell longer in questioning. It also encourages the collection of evidence to determine whether the perceived issues as initially formulated are actually the problems and allows time and space to gather student responses. The course release time provided to faculty members at this point is critical in allowing them to engage in a slower process than their full schedules generally allow.

It is important to recognize longstanding critiques of one-way linear processes that may overemphasize sequential actions when using any model. Such criticisms underscore tensions between the benefits of moving logically through foundational steps and the challenges of being agile in the face of complex, ongoing issues. To address these tensions between clarity and rigidity, those conducting curricular design in practice often encounter reflective metaquestions, including whether a particular approach is "a linear, sequential process, or is it iterative and nonlinear? Or both?” (Willis, 1995, p. 13). Linear, "waterfall" process approaches are critiqued in the literature as representing a "manufacturing mindset," (see for example Pope-Ruark, 2017, p. 11-26), with more flexible and incremental approaches recommended. The process we describe has a linear element in that we attempt to complete one phase before proceeding to the next. However, the process is not entirely one-way or rigid: it can easily have smaller iterative eddies and feedback loops as needed. It is always possible to cycle back to further inquiry if more information is needed in later phases, and it is also possible to do another iteration of imagining if institutional barriers prevent hoped-for innovations. However, the benefit of the model is in holding back decision-making and action until adequate exploration has occurred. For example, while participating in the early stages of a program curriculum project, instructors may be keen to re- 
work a particular assignment that crosses over several interrelated courses. But in the context of the overall redesign, the developers are able to remind team members that we are currently in the Inquire phase, and before jumping into changing the assignment, we want to spend more time thinking about the underlying purpose of the courses, define the outcomes of the entire suite, and speak to students about how the current assessment model is working for them. From our experience, this will result in a stronger assessment design in the end.

\section{Mitigating Potential Challenges}

In an ideal world, educational developers would have access to all the relevant information and all stakeholders in order to effectively apply the 3-I approach. However, challenges may arise when not everyone who is affected by curriculum decisions is able to join the discussion table. While the adapted model offers a flexible and effective framework for educational developers working with faculty colleagues on their course and program (re)designs, it is important to recognize that this framework may at times be limited by parameters beyond the educational developer's authority or purview. We encountered one such example when key administrators were not involved early enough in the process, until nearly the completion of the project. We discovered that the changes we were so excited about were not possible due to meso level control. We learned that when decision-makers are not part of the redesign team, they need to be brought into the conversation at key points in the Inquire and Imagine phases. This early involvement surfaces constraints that may otherwise remain hidden during the Innovate phase, and it positions decision-makers as key stakeholders throughout the process rather than simply as an audience at the end.

Like our faculty colleagues who must negotiate which solutions to their curricular problems are both most needed and most feasible, educational developers often navigate and respond creatively to often unpredictable constraints surrounding each curriculum design process. In order to mitigate potential challenges that can arise, we recommend identifying and, where appropriate, engaging with key issues and stakeholders at each level (micro, meso, and macro) of influence from the beginning of the project. Initiating the process in this way will enable those involved in the project to effect meaningful change within and between the appropriate levels of influence from the outset and on an ongoing basis.

\section{Looking to the Future}

Our team continues to update this model as we work with it, applying it with different groups in a variety of academic disciplines. While we sometimes connect with a team or individual, by request, to do follow-up data collection the year after the course redesign, this is currently not a formal part of the process. Practical constraints mean that faculty members are busy with implementation and their course release is over, the reports have been written and decisions made, and we are initiating our next round of projects. To improve our model, we would like to add another 'I' to the model, such as Impact, to make the process more holistic. The addition of a formal phase in which we can assess impacts of curricular changes could be factored in to the lifecycle of the process, and stakeholders could therefore be made aware of any additional time and resources needed to undertake this phase. Is it best to evaluate the first iteration, or better to wait until things have been refined through one or two implementation cycles? How does the information gathered during the Impact phase then relate to curriculum renewal that may restart the cycle with a new Inquire phase? These are some of the questions we consider as we work through our curriculum changes and update the model. 
It is important to move from being tacit to explicit when articulating and sharing educational development approaches. Such explicit explanation holds value for our own purposes and for creating meaningful dialogue with others in our field. Interestingly, when we presented the 3-I model to our colleagues at the 2018 annual conference of the Society for Teaching and Learning in Higher Education, they told us that the most useful followup to the session would be an online resource. However, in doing further review for the purposes of this paper, we discovered that other Canadian developers have created parallel and complementary processes (e.g., Kenny 2013; Gwenna Moss Centre for Teaching and Learning, n.d.) that were already available online. Thus, we have noticed that those in the educational development community (including ourselves) could make more adequate use of materials shared by other centres, in addition to turning to published literature. Like educators, developers often find themselves 're-inventing the wheel' when it comes to their processes and programming. We see a need to expand leadership in educational development that fosters further sharing of materials, models, and practices across Canadian postsecondary contexts in a more formalized way. We can expand our efforts nationally by increasing collective educational development contributions at the mega level (Simmons, 2016). To this end, we see great value in expanding inter-institutional dialogue by collaboratively working to build our engagement of these issues, whereby we can improve the connections between centres for teaching and learning nationally. Our hope in sharing this work is to support other educational developers in their curriculum work, and we invite feedback and further collaboration in the future.

\section{References}

Gwenna Moss Centre for Teaching and Learning. (n.d.) Curriculum development and renewal. Retrieved from https://teaching.usask.ca/curriculum/curri culum-development.php

Hubball, H., Pearson, M., \& Clarke, A. (2013). SoTL Inquiry in Broader Curricular and Institutional Contexts: Theoretical Underpinnings and Emerging Trends. Teaching \& Learning Inquiry: The ISSOTL Journal, $\quad$ 1(1), 41-57. https://doi.org/10.2979/teachlearninqu.1.1 .41

Kenny, N. (2013, August 31). SOARing through Curriculum Development Processes [Blog post]. Retrieved from https://natashakenny.wordpress.com/tag/ soar/

Knight, P.T. (2001). Complexity and curriculum: A process approach to curriculum-making. Teaching in Higher Education, 6(3), 369-381. https://doi.org/10.1080/135625101200612 23

Poole, G., \& Simmons, N. (2013). Contributions of the Scholarship of Teaching and Learning to Quality Enhancement in Canada. In R. Land \& G. Gordon (Eds.), International Studies in Higher Education: Enhancing Quality in Higher Education (pp. 118-129). Florence, KY: Routledge.

Pope-Ruark, R. (2017). Agile faculty: Practical strategies for managing research, service, and teaching. Chicago: University of Chicago Press.

Rutgers, The State University of New Jersey. 2018. Managing change. Retrieved from https:// cornerstone.rutgers.edu/managingchange

Simmons, N. (2016). Synthesizing SoTL Institutional Initiatives toward National Impact. New Directions for Teaching and Learning, 2016(146), 95-102. http://doi.org/10.1002/tl.20192 
Stavros, J. M., Cooperrider, D. L., \& Kelley, D. L. (2003). Strategic inquiry appreciative intent: inspiration to SOAR, a new framework for strategic planning. AI Practitioner. November, 10-17.

Stavros, J. M., \& Hinrichs, G. (2009). Chapter 4: How to SOAR using the 5-I's. In S.A. Hammond (Eds.), The Thin Book of SOAR: Building Strengths-based Strategies. Bend, OR: Thin Book Publishing Co., 22-30.

Srivastra,S. \& Cooperrider, D.L. (1990). Appreciative management and leadership: The power of positive thought and actions in organizations. San Francisco: Jossey-Bass.

Williams, A. L., Verwoord, R., Beery, T. A., Dalton, H., Mckinnon, J., Strickland, K., ... Poole, G. (2013). The power of social networks: A

\section{Biographies}

Michelle Yeo is an Associate Professor and Faculty Development Consultant in the Academic Development Centre at Mount Royal University. She is also the Academic Director of the Institute for the Scholarship of Teaching and Learning.

Jennifer Boman is an Associate Professor and Faculty Development Consultant in the Academic Development Centre at Mount Royal University. Her research interests include faculty development, faculty conceptions of assessment, and teaching and learning in higher education.

Julie A. Mooney is an Educational Development Specialist at the Gwenna Moss Centre for Teaching and Leaning at the University of Saskatchewan and a former Faculty Development Consultant with the Academic Development Centre at Mount Royal University. model for weaving the scholarship of teaching and learning into institutional culture. Teaching and Learning Inquiry: The ISSOTL Journal, 1(2), 49-62. https://doi.org/10.20343/teachlearninqu.1. 2.49

Willis, J. (1995). A recursive, reflective instructional design model based on constructivistinterpretivist theory. Educational Technology, 35(6), 5-23. Retrieved from https://www.jstor.org/stable/44428302

Wolf, P. (2007). A model for facilitating curriculum development in Higher Education: A faculty-driven, data-informed, and educational-developer-supported approach. New Directions in Teaching and Learning, 112, 15-20. https://doi.org/10.1002/tl.294

Andrea Phillipson is an Assistant Professor and Faculty Development Consultant in the Academic Development Centre at Mount Royal University. Her interests include social justice in higher education, writing pedagogy, and learning spaces.

Luciano da Rosa dos Santos is an Assistant Professor and Faculty Development Consultant in the Academic Development Centre at Mount Royal University. His research interests include educational development, educational technologies, and learning spaces (both physical and online).

Erika E. Smith is an Assistant Professor and Faculty Development Consultant in the Academic Development Centre at Mount Royal University. Her research interests include undergraduate digital literacies and social media use for learning, faculty development, and educational technologies. 